Sergio Lodde

Università di Cagliari e CRENoS

\title{
HUMAN CAPITAL AND GROWTH IN THE EUROPEAN REGIONS. \\ DOES ALLOCATION MATTER?
}

\begin{abstract}
The paper examines the relationship between the allocation of human capital among different activities and economic growth in the context of the European regions. A proxy of the allocation of the labor force to technical activities is constructed using data about occupations at the regional level and included in cross section growth regressions together with various educational variables (primary, secondary and higher education years and shares). The main results of the paper are the following: the educational variables become insignificant when country dummies are included in the regressions suggesting that, due to differences in the national education systems, they capture the effects of some omitted country specific variable; on the other hand a robust correlation emerges between the allocational variable and the regional rate of growth in the period 1981-91.
\end{abstract}





\section{H uman capital and growth: a controversial relationship}

The purpose of this paper is to give a contribution to the analysis of the relationship between human capital and growth in a regional context. Particularly the central question is whether taking account of the allocation of human capital among different activities which may be more or less growth enhancing, helps to clarify why this factor, theoretically so relevant in the growth literature, fails to give consistent results in the empirical analysis.

Recently the relationship between human capital and growth has been studied in several papers (Romer, 1990; Barro, 1991, 1996; Mankiw, Romer, Weil, 1992; Levine, Renelt, 1992; Wolff, Gittleman, 1993; Benhabib, Spiegel, 1994; Islam, 1995; Pritchett, 1995) but the results are still controversial.

Barro (1991), and Mankiw-Romer-Weil (1992) analyse the cross section relationship between initial endowment of human capital and growth using the enrollment rates to primary and secondary school as a proxy of the human capital input. In both studies a positive and significant correlation has been found between human capital and the rate of growth of per capita income'. Using literacy rates as a proxy for human capital Romer finds an indirect effect on growth through investment. The robustness of these variables has also been confirmed in the sensitivity analysis conducted by Levine and Renelt (1992).

However the use of the enrollment rates as a proxy of the stock of human capital implies very strong assumptions which raise some doubts on the correct interpretation of the results. The stock must be the steady state one for all the economies in the sample and the rates must be constant across time and countries ${ }^{2}$.

Thanks to the availability of some new data sets developed with different estimation methodologies (Kyriacou, 1991; Barro-Lee, 1993; 1996; NehruSwanson-D ubey, 1994) data on educational attainment have been introduced in growth regressions. Barro (1996) finds a positive and significant partial correlation between growth and educational attainment, measured by the

\footnotetext{
${ }^{1}$ It must be noted anyway that the high R squared obtained by Mankiw Romer and Weill depends stongly on the chosen proxy for human capital. They ignore primary education and this affects substantially the variability of the human capital stock measure. Secondary enrollment rates vary by more than primary ones increasing the disparity within the sample. Following this objection Klenow and Rodriguez (1977) rerun the MRW regression obtaining a R squared value of 0.48 compared to the 0.78 of the original estimation.

${ }^{2}$ Pritchett (1995) points out that the justification for putting enrollment rates into growth regressions is that they are a proxy for the flow of investment in human capital which is a proxy for the change of the stock of human capital in the labour force. He shows that this assumption is incompatible with the empirical evidence since there is a clear and significant negative correlation between measures of the actual growth of the stock of human capital and initial enrollment rates.
} 
average years of schooling in primary and secondary school, in a sample of 100 countries. Benhabib and Spiegel (1994) find a negative and insignificant correlation estimating a standard Cobb D ouglas production function. However they show that education plays a relevant role in the catch-up proces. A negative and insignificant relationship emerges also in the analysis of Pritchett (1995) and Islam (1995).

A more detailed analysis has been conducted by Wolff and Gittleman (1993) who estimate the effects on growth of different levels of educational attainment. The comparative role of primary, secondary school and higher education in the catch-up process is analysed in a sample of more than one hundred countries using both data on enrollment rates and educational attainment. The authors find that, though both enrollment rates and educational attainment levels are significant in the whole sample, the former perform uniformly better than the latter. Moreover when investment is introduced in the regressions the coefficients of the educational measures become all insignificant. Their explanation is that education plays an indirect role in the catch-up process: the availability of more educated work force acts as a stimulus to investment thereby exerting an indirect effect on growth.

An interesting result of their analysis comes from the sample of industrialized countries. Here the educational variables seem to exert no effect on growth and catch-up. Particularly disconcerting is the fact that higher education does not play any role whatsoever. This result is at odds with conventional wisdom which sees scientific knowledge and technical expertise as a strongly influential factor in the catch-up process. This kind of knowledge should be mainly embodied in the share of the work force endowed with higher education.

Summarizing these findings suggest that higher enrollment rates to primary and secondary school are positively and significantly correlated with higher rates of growth of per capita income but this is seldom true for educational attainment levels. In the latter case the empirical evidence does not corroborate the theoretical hypothesis of a positive and direct effect of human capital (to be more precise: education) on growth.

How can we explain the significance of the enrollment rates coefficients in the light of these controversial results? Are the enrollment rates a good proxy for human capital or are they just strictly correlated to some omitted variable? Why is the performance of attainment levels so disappointing considering that they should beabetter proxy of the human capital embodied in the work force?

\footnotetext{
${ }^{3}$ In fact attainment levels can be regarded as a proxy of the educational achievement of current
} 
Different arguments have been proposed to explain these controversial results. In a recent paper Bils and Klenow (1995) argue that the causal relationship is probably inverted, namely growth drives education and not the other way around. Just as faster growth induces more investment in physical capital it could induce people to acquire more education. This explains why enrollment rates are significant in growth regressions while attainment levels are not. The former react quickly to variations in the growth rate, on the contrary it takes longer time for a significant change in the education stock of the active population to take place.

Another line of criticism questions the representativity of the variables used in the analysis. Education captures just one aspect of human capital complexity since it does not include the experience accumulated on the job (Pritchett, 1995) and differences in school quality (Islam, 1995).

Some researchers attempt to define an indirect relationship between human capital and growth. In this view human capital is not the engine of growth rather it is its fuel. According to Benhabib and Spiegel (1994) human capital has an indirect impact on growth because it facilitates the adoption of new technologies in the economy and makes technological catch-up faster.

Another possibility is that education is a threshold factor which makes the difference when we analyze a sample of economies some of which are below and some others above it (for example developing and rich countries or countries at a different development stage), but becomes less relevant when all countries in the sample are above the threshold, that is are all rich ${ }^{4}$.

Finally another stream of literature points out that the cognitive abilities generated by education are not necessarily growth enhancing if applied to redistributive and rent seeking activities instead of socially productive and innovative ones (Wolff, Gittleman, 1993; Pritchett, 1995). Since this allocation may be very different across countries the use of an aggregate variable as a proxy of human capital tends to obscure some relevant aspects of its relationship with growth.

The last point has been stressed in several theoretical works. In his analysis of institutional change North (1990) gives a powerful example of how the institutional structure can deviate knowledge from socially productive uses and stimulate the development of skills more suited to redistributive activities. In the

\footnotetext{
labour force while the attainment levels reflect that of future labour force.

${ }^{4}$ See Azariadis and D razen (1990). This would explain, by the way, why Wolff and Gittleman (1993) find a significant partial correlation between education and growth in a large sample of countries and no correlation at all in a restricted sample of industrialised countries.
} 
sixteenth century successful piracy required profound knowledge about naval warfare, trade routes, armament and so on, while to be an industrial entrepreneur in the twentieth century implies very different skills.

"If the basic institutional framework makes income redistribution (piracy) the preferred economic opportunity, we can expect a very different development of knowledge and skills than a productivity increasing (a twentieth century chemical manufacturer) economic opportunity would entail. The incentives that are built into the institutional framework play the decisive role in shaping the kinds of skills and knowledge that pays off" (North 1990).

A similar point is made by Baumol in his analysis of entrepreneurship (Baumol 1990). He argues that while the supply of entrepreneurs varies among countries, their contribution to growth varies much more because a considerable part of their talent is allocated to unproductive activities like rent seeking and crime instead of production and innovation ${ }^{5}$. Baumol provides several historical examples of societies like ancient Rome or medieval China, where the structure of rewards attracted talented people to unproductive activities. He shows that there are signs of technological stagnation or reduced ability to take advantage of technical knowledge in these societies.

Romer in his 1990 paper on human capital and growth stresses the importance of the allocation of human capital to the research sector since the accumulation of knowledgehence therate of growth of theeconomy depend on it.

Murphy, Vishny and Schleifer (1991) make an attempt to formalize the problem. In their model when talented people become entrepreneurs they improve technology and productivity grows, when they become rent seekers most of their returns come from redistribution rather than production of wealth. As a result, talented people do not direct their efforts to improving technology, and the economy stagnates. If the most talented become rent seekers the ability of entrepreneurs is lower, therefore innovation activity and growth are likely to slow down.

Testing the model empirically they find that a higher share of engineers is positively and significantly correlated with income per capita growth while the

\footnotetext{
5 According to Baumol the term "unproductive activities" refers to all activities which do not contribute directly or indirectly to the net output of the economy. In this sense financial activities are productive as well as "[...] anything that contributes to the output of any good or service desired by consumers, even if that product is not approved of by society" (Baumol, 1990).
} 
opposite is true for lawyers. Some evidence in this direction comes also from Laband and Sophocleus (1987), Magee, Lebrock, Y oung (1989), Lodde (1995).

This paper examines the relationship between education and economic growth in a sample of European regions and attempts to test the hypothesis that the allocation of skills and knowledge embodied in the educated labor force among different activities influences the rate of growth of regional economies and the speed of the convergence process. The test is done using data on the educational attainment of the active population and on its distribution among various occupations. The next section is dedicated to describe the dataset used in the analysis. The third provides some descriptive statistics on education in the sample of regions under analysis. The fourth reports econometric results on the effects of the educational attainment of the labour force on productivity growth and convergence. In the fifth a proxy of the allocation of educational skills to technical activities is introduced to test the hypothesis that growth is mainly influenced by the latter. The last contains conclusive remarks.

\section{The dataset}

While the recent empirical literature on human capital and growth has produced a considerable number of studies, few have focused on industrialized countries $^{6}$. This is probably due to the lack of a sufficient number of observations when national data are used. An analysis at the regional level helps to overcome this problem but raises other difficulties. While some data sets of harmonized data are available at the national level (World Bank, Unesco, Barro and Lee 1996, to quote a few) no harmonization has been done in Europe at the regional level. Starting from 1993 Eurostat provides data classified according to the ISCED classification implemented by UNESCO ${ }^{7}$ but they are too recent to be used in growth regressions. Thus an attempt has been made to harmonize census regional data from some European countries by grouping the available classes into three categories which correspond approximately to the Eurostat classification: primary and lower secondary school, upper secondary school and higher education ${ }^{8}$. The variables used in the econometric analysis are the

${ }^{6}$ Jorgenson and Fraumeni have studied this problem for the United States (Fraumeni and Jorgenson 1992). Wolff and Gittleman (1993) estimated the effetcs of educational variables isolating a sample of industrialised countries.

${ }^{7}$ More precisely the classes are 0-2, 3 and 5-7 of the ISCED classification which correspond to primary and lower secondary, upper secondary and higher education.

${ }^{8}$ The classes have been defined according to the Eurostat classification. Primary includes the active population with no education or no declared degree as well as primary and lower secondary education. The class secondary includes upper secondary schooling, finally higher includes 
average values of the share of the active population who possess a qualification in primary, secondary and higher education respectively in the period 1981-91. Since annual observations are not available the series have been calculated as the average value of the two censuses occurred at the beginning and the end of the relevant period or in the closest year?. Unfortunately the census dates for Germany are very different from the other countries, after 1970 there has been only one census in 1987. Thus mid point observations instead of average values have been used for this country. The data for UK come from Labour Force Surveys ( 1981, 1991).

The choice of average values instead of initial ones can be justified on the ground that they are better indicators of the educational input during the period under test. Doing this we are assuming away feedback effects of growth on education but this should not be a serious problem since the period is relatively short. The ratio for this assumption is that enrollment rates react positively to the expected rate of growth but this is less likely to be the case for attainment levels since it takes long time for the former to produce significant changes in the latter.

Due to the complex structures of the European national education systems and the differences among them, achieving a reasonable degree of comparability is not an easy task. Depending on the country some types of degrees and diplomas classified within the same category require a different number of years of education. The French and German systems for example are much more complex then the Italian and offer more options to students. Thus, while in Italy the upper secondary level implies in most cases thirteen years of schooling, it includes much more variable curricula in the other two countries. Taking this shortcomings into account another proxy of educational attainment has been constructed: the average years of schooling. This measure is probably more precise and comparable than the previous ones but, being a global measure, does not allow to analyse the separate effects of different educational attainment levels on economic growth. Therefore three more variables have been added measuring the average years of primary, secondary and higher education.

To test the central hypothesis of this paper a proxy of the allocation of human capital to technical activities has been built. The main source of such information are labor force surveys data on the distribution of the active

university and not university courses at a level higher than upper secondary.

${ }^{9}$ In France there have been two censuses in 1982 and 1990. 
population among different occupations. Eurostat collects EU labour force surveys including information on the professional composition of the active population at the regional level. The database covers the period from 1983 up to 1995. These data have been harmonized according to the International Standard Classification of O ccupations known as ISCO 68 for the period 198391 and according to the new classification ISCO 88 thereafter. The harmonization is not complete, at the three digits level figures are not comparable in many cases because European countries use different classifications and definitions of specific occupations. Nevertheless they can be used fairly reliably at a more aggregate level.

From this dataset an attempt has been made to construct a measure of the share of the active population occupied in scientific and technical activities requiring higher or upper secondary education skills. The classification is composed of seven main groups: Professionals, technical and related workers; administrative and managerial workers; clerical and related workers; sales workers; service workers; agricultural, animal husbandry and forestry workers, fishermen and hunters; production and related workers, transport equipment operators and labourers. The measure has been constructed drawing from the first group which includes mostly professionals and highly skilled technicians. Particularly the following subgroups have been included: physical scientists and related technicians; architects, engineers and related technicians; life scientists and related technicians; statisticians, mathematicians, system analysts and related technicians. In this case too average values have been calculated although the assumption of no feedback effects is much more questionable. To take this problem into account initial values of this variable (1983) have been used in some regressions.

The economic variables used in the analysis are the rate of growth of productivity (value added per worker) in the period 1981-91, the initial value of productivity and the average share of investment in value added in the same period. The data come from the CRENOS (Centro di Ricerche Economiche Nord Sud) data base on the European regions and the "Regio 2" data bank from Eurostat. The value added per worker has been preferred to the rate of growth of GDP per capita - commonly used in growth regressions - because the former is a measure of the dynamics of productivity while the latter is rather an indicator of welfare (Wolff 1994, Paci 1996). Thus the choice is justified on the ground that the hypothesis being tested here is that the allocation of human capital affects mainly the rate of innovation hence the dynamics of productivity. All variables are expressed in purchasing power parity units at constant 1985 prices. 
The data set includes 66 regions from five countries: Germany, France, Italy, Belgium and United Kingdom ${ }^{10}$. The sample is only partially representative of the whole European Union. Northern regions are over represented with respect to southem ones and this fact is likely to cause a bias in convergence speed estimation. The definition of the regions included varies across countries. For Italy and France the NUTS-2 level has been chosen, while The NUTS-1 level seems more appropriate in the cases of Germany and Belgium ${ }^{11}$. As regards U.K. eleven Standard Regions have been considered as units of analysis.

\section{Education in the European regions: some descriptive evidence}

Despite the fact that all regions in the sample belong to industrialized countries there are considerable differences in the educational qualifications of the active population.

Table 1 reports standard statistics of the educational variables. As regards total years of schooling the highest value is found in a German region (Hambourg with 11 years) while the lowest belongs to Italy (Basilicata with 7.4). The widest variation can be found, as expected, in higher education, here again a German region (Berlin) is at the top and an Italian one (Valle d'Aosta) at the bottom. The ratio of the two values is nearly four.

German active population is in general the most educated. All German regions show higher values of total years of schooling (between ten and eleven years on the average) and secondary education than any other in the sample as can be easily seen from table 2 below. Most of the regions in the sample are concentrated in the third and fourth classes (between 8 and 9 years of schooling), they belong mainly to France and UK while the Italian regions are all concentrated in the last three classes. As regards higher education the German regions show again the highest values but comparable levels can be found also in the Paris (Ile de France) and London (South east) regions. Belgium France and UK are somewhat in the middle while Italian labour force has the lowest number of years of higher education.

Table 1. Measures of dispersion of active population educational attainment across the European regions. Average years of schooling 1981-91.

\footnotetext{
10 The regions of the countries included in the sample are 67 actually, however Corse has been dropped because of missing data for occupations.

${ }^{11}$ For a more detailed explanation of the reasons behind this choice of the regional units see Paci (1996).
} 


\begin{tabular}{lrrrr}
\hline & Primary & Secondary & Higher & Total \\
\hline Mean & 3.122 & 3.865 & 1.897 & 8.884 \\
Median & 2.837 & 3.826 & 1.659 & 8.605 \\
Maximum & 4.975 & 6.109 & 3.496 & 11.040 \\
Minimum & 1.571 & 2.365 & 0.868 & 7.396 \\
Std. D ev. & 0.843 & 0.925 & 0.740 & 0.852 \\
Skewness & 0.547 & 0.349 & 0.531 & 0.904 \\
Kurtosis & 2.185 & 2.193 & 2.047 & 2.896 \\
\hline
\end{tabular}

Sources: Census of population for Belgium, France, G ermany and Italy; Labour Force Survey for United Kingdom.

Table 2. Distribution of the sample regions among classes of educational attainment. Total years of schooling and years of higher education. Average values 1981-91

\begin{tabular}{lrrrrrrrrr}
\hline & \multicolumn{4}{c}{ Total years of schooling } & \multicolumn{4}{c}{ Years of higher education } \\
\hline & $10>$ & $9-10$ & $8.5-9$ & $8-8.5$ & $<8$ & $3>$ & $2-3$ & $1-2$ & $<1$ \\
\hline Germany & 11 & 0 & 0 & 0 & 0 & 6 & 5 & 0 & 0 \\
France & 0 & 2 & 12 & 7 & 0 & 1 & 4 & 16 & 0 \\
UK & 0 & 0 & 6 & 5 & 0 & 1 & 9 & 1 & 0 \\
Italy & 0 & 2 & 4 & 9 & 5 & 0 & 0 & 15 & 5 \\
Belgium & 0 & 3 & 0 & 0 & 0 & 0 & 1 & 2 & 0 \\
\hline
\end{tabular}

Sources: Census of population for Belgium, France, Germany and Italy; Labour Force Survey for United Kingdom.

Table 2 shows also another feature of the educational variables behaviour. It is possible to recognize national clusters: most of the regions of each country are concentrated in the same or in contiguous classes. This behaviour reflects different institutional aspects of the national education systems. The educational attainment levels of the active population are influenced by several factors such as income per capita, the distribution of earnings or the structure of the labour market which may vary considerably even across regions of the same country, however they benefit from a common education policy which tends to reduce the range of variation within the boundaries of each country. The presence of 
national patterns appears clearly taking a look at the coefficients of variation (measured by the ratio of the standard deviation to the mean) in table 3. For all levels of education they are much lower within each country than in the whole sample. Leaving aside Belgium for which we have only three observations, G ermany has the most omogeneous educational structure across regions ${ }^{12}$ while the highest dispersion is found in the Italian subset. In general variability increases together with the education level, the only exception being again Germany where values are reversed.

\footnotetext{
${ }^{12}$ D espite the higher political and administrative authonomy of the länder
} 
Table 3. Coefficient of variation of the educational variables within each country and in the whole sample.

\begin{tabular}{lrrrr}
\hline & Primary & Secondary & Higher & Total \\
\hline Belgium & 12.9 & 3.4 & 33.0 & 1.0 \\
Germany & 13.8 & 7.0 & 6.7 & 2.5 \\
France & 6.1 & 6.8 & 21.1 & 3.5 \\
United Kingdom & 2.5 & 4.2 & 13.5 & 2.6 \\
Italy & 7.5 & 12.3 & 18.8 & 5.9 \\
Whole sample & 27.1 & 23.9 & 38.9 & 9.6 \\
\hline
\end{tabular}

Sources: Census of population for Belgium, France, Germany and Italy; Labour Force Survey for United Kingdom.

\section{Econometric results}

The main purpose of the econometric analysis is to test whether education has contributed significantly to the growth and convergence performance of the regions in the sample and, if this has not happened, to provide a possible explanation. The standard estimated equation is of the form:

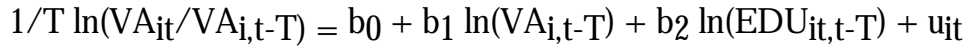
where $\mathrm{VA}_{\text {it }}$ is the final value of value added per worker measured in ppp units, $\mathrm{VA}_{\mathrm{i}, \mathrm{t}-\mathrm{T}}$ is the initial one and $\mathrm{EDU} \mathrm{Uit}_{\mathrm{t}, \mathrm{t}-\mathrm{T}}$ is the average value of the educational variables during the period 1981-91. We use seven different measures of the educational input: total average years of schooling, average years of primary, secondary and higher education and the shares of the three levels. All variables are in logarithms, results are reported in table 4 and 5.

If education is a relevant explanatory variable in this process we would expect positive and significant coefficients for the educational variables and a higher convergence speed among the regions of the sample holding education constant. In other terms regions with similar educational inputs should converge at a faster rate. At first glance results partially confirm this expectation. 
Table 4. Convergence in productivity among the European regions. Average years of total, primary, secondary and higher education. 1981-91

Dependent variable is the average rate of growth of value added per worker 1981-91

Estimation method OLS

Number of observations: 66

\begin{tabular}{llllll}
\hline & 1 & 2 & 3 & 4 & 5 \\
\hline CONSTANT & 0.172 & 0.176 & 0.194 & 0.210 & 0.168 \\
& $(5.57)$ & $(5.85)$ & $(6.85)$ & $(7.00)$ & $(5.83)$ \\
LOGVA81 & -0.015 & -0.018 & -0.016 & -0.020 & -0.015 \\
& $(-4.85)^{* *}$ & $(-5.42)^{* *}$ & $(-5.87)^{* *}$ & $(-6.39)^{* *}$ & $(-5.15)^{* *}$ \\
LOGTOTYEARS & & 0.013 & & & \\
& & $(2.14)^{*}$ & & & \\
LOG PRIYEARS & & & -0.007 & & \\
& & & & $(-4.01)^{* *}$ & \\
LOG SECYEARS & & & & 0.008 & \\
& & & & $(3.72)^{* *}$ & \\
LOGHIG HYEARS & & & & & 0.004 \\
& & & & & 0.38 \\
R2 adj. & 0.26 & 0.30 & 0.40 & 0.38 & 0.35 \\
F test & 23.5 & 14.7 & 22.6 & 21.0 & 18.7 \\
\hline
\end{tabular}

$* *=$ significant at $1 \%$ level

$*=$ significant at $5 \%$ level

The first equation in table 2 is an estimate of unconditional convergence in the sample. The coefficient of initial value added per worker is negative and significant showing that a process of convergence of this type has taken place during the period under test although at a slow pace. Introducing the educational variables adds little to the convergence process. Particularly the speed of convergence increases holding constant total and secondary years of schooling in regression 2 and 4 while the effect of higher education in regression 5 is null. 
In general the presence of the educational variables raises the explanatory power of the regressions although not dramatically. The effects of the educational variables on the rate of growth of productivity are rather weak, however the coefficients display the expected signs, particularly they are negative for primary education and positive for secondary and higher, and are all significant at the one per cent level. The coefficient of total years of education is also significant reinforcing the impression that education plays a role - albeit not a primary one - in the growth and convergence processes.

Results are roughly the same if we make use of the other measures of the educational input namely the shares of primary, secondary and higher education in the labour force as shown in table 3.

Again signs are as expected and the coefficients of both secondary and higher education are highly significant while the explanatory power is nearly the same as before. In the last two regressions we control for differences in investment rates to test whether the effects of education on growth are direct or indirect as suggested by Romer (1990), Wolff and Gittleman (1993) and Benhabib and Spiegel (1994). According to these authors education does not affect productivity growth directly, rather it acts as a stimulus or as a complementary factor to investment in physical capital which, in turn, influences the rate of growth. The empirical implication of this hypothesis is that the educational variables should become insignificant when the investment share on output is added to the regressors ${ }^{13}$. This does not happen in our case, the coefficients of the educational variables are not affected though the coefficient of initial productivity decreases and the overall fit of the regressions worsens substantially ${ }^{14}$.

\footnotetext{
${ }^{13}$ Unfortunately data on investment rates are not available for the whole sample analyzed here, United Kingdom and Belgium have been excluded for this reason.

${ }^{14}$ Investment rates are never significant in our sample. This is a puzzling result since investment rates are regarded as a very robust regressor in the growth regressions literature (Levine and Renelt, 1992). However it confirms other findings on the European regions growth (Fagerberg and Verspagen, 1996). No significant correlation has been found between investment and education, Regressing the former on any educational variable gives negative and insignificant coefficients (results are not reported for brevity).
} 
Table 5. Convergence in productivity with education. Shares of primary, secondary and higher education. Average values 1981-91

D ependent variable is the average rate of growth of value added per worker 1981-91

Estimation method OLS

Number of observations: 66

\begin{tabular}{llllll}
\hline & 1 & 2 & 3 & 4 & 5 \\
\hline CONSTANT & 0.203 & 0.227 & 0.178 & 0.171 & 0.159 \\
& $(6.75)$ & $(7.42)$ & $(6.33)$ & $(2.52)$ & $(2.93)$ \\
LOGVA81 & -0.018 & -0.020 & -0.015 & -0.014 & -0.013 \\
& $(-6.07)^{* *}$ & $(-6.61)^{* *}$ & $(-5.21)^{* *}$ & $(-2.12)^{*}$ & $(-2.48)^{*}$ \\
LOGPRI & -0.007 & & & & \\
& $(-3.36)^{* *}$ & & & & \\
LOG SEC & & 0.007 & & & 0.006 \\
& & $(4.16)^{* *}$ & & & \\
LOGHIGH & & & & 0.004 & \\
& & & $(3.73)^{* *}$ & & \\
LOGINV & & & & & -0.002 \\
R2 adj. & 0.36 & 0.41 & 0.38 & 0.21 & 0.11 \\
F test & 19.3 & 23.4 & 21.1 & 5.4 & 3.15 \\
Num.obs. & 66 & 66 & 66 & 52 & 52 \\
\hline
\end{tabular}

t- statistics in parentheses, corrected for heteroschedasticity when detected

$* *=$ significant at $1 \%$ level

$*=$ significant at $5 \%$ level

These results are somewhat at odds with other findings mentioned above on the relationship between educational attainment measures and economic growth in national industrial economies ${ }^{15}$. Actually this contrast is only apparent as we shall see below. As we already pointed out before the educational qualification of the labour force is influenced by national education policies,

15 The paper of Wolff and Gittleman is an already quoted example. They find insignificant coefficients for all the educational variables in a sample of industrialized countries. 
therefore it tends to follow a country specific pattern of behaviour ${ }^{16}$. Due to this fact the educational measures are likely to capture the effects of some country specific omitted variable on the growth of productivity. To check for this possibility country dummies have been introduced in the regressions.

\footnotetext{
${ }^{16}$ The coefficient of variation within each country is much smaller than in the whole sample for all educational variables. See table 1. There could be also a measurement error which follows national profiles due to problems of comparability among the European national education systems. However this is more likely to have occurred for the shares of primary, secondary and higher education because these categories are not perfectly suited for taking these differences into account. The other measures based on average years of education are more precise and should be much less influenced by problems of this type. Finally the variable totyears is only marginally affected.
} 
Table 6. Convergence in productivity with education and country dummies. Average years of primary, secondary and higher education. 1981-91

Dependent variable is the average rate of growth of value added per worker 1981-91

Estimation method OLS

Number of observations: 66

\begin{tabular}{|c|c|c|c|c|c|}
\hline & 1 & 2 & 3 & 4 & 5 \\
\hline CONSTANT & $\begin{array}{l}0.147 \\
(5.56)\end{array}$ & $\begin{array}{l}0.140 \\
(5.20)\end{array}$ & $\begin{array}{l}0.148 \\
(5.17)\end{array}$ & $\begin{array}{l}0.142 \\
(4.36)\end{array}$ & $\begin{array}{l}0.146 \\
(5.04)\end{array}$ \\
\hline LOGVA81 & $\begin{array}{l}-0.012 \\
(-4.63)^{* *}\end{array}$ & $\begin{array}{l}-0.014 \\
(-4.71)^{* *}\end{array}$ & $\begin{array}{l}-0.013 \\
(-4.70)^{* *}\end{array}$ & $\begin{array}{l}-0.011 \\
(-3.16)^{* *}\end{array}$ & $\begin{array}{l}-0.012 \\
(-4.32)^{* *}\end{array}$ \\
\hline DUMIT ${ }^{(a)}$ & $\begin{array}{l}-0.006 \\
(-6.02)^{* *}\end{array}$ & $\begin{array}{l}-0.005 \\
(-4.67)^{* *}\end{array}$ & $\begin{array}{l}-0.007 \\
(-3.65)^{* *}\end{array}$ & $\begin{array}{l}-0.006 \\
(-3.23)^{* *}\end{array}$ & $\begin{array}{l}-0.005 \\
(-3.01)^{* *}\end{array}$ \\
\hline DUMGE ${ }^{(a)}$ & $\begin{array}{l}-0.002 \\
(-1.97)^{*}\end{array}$ & $\begin{array}{l}-0.004 \\
(-2.24)^{*}\end{array}$ & & & $\begin{array}{l}-0.003 \\
(-2.11)^{*}\end{array}$ \\
\hline LOGTOTYEARS & & $\begin{array}{l}0.011 \\
(1.26)\end{array}$ & & & \\
\hline LOG PRIYEARS & & $\begin{array}{l}0.004 \\
(1.15)\end{array}$ & & & \\
\hline LOGSECYEARS & & & $\begin{array}{l}-0.001 \\
(-0.26)\end{array}$ & & \\
\hline LOGHIG HYEARS & & & & $\begin{array}{l}0.002 \\
(0.93)\end{array}$ & \\
\hline R2 adj. & 0.52 & 0.52 & 0.50 & 0.51 & 0.51 \\
\hline $\mathrm{F}$ test & 24.1 & 18.7 & 22.5 & 17.8 & 18.3 \\
\hline
\end{tabular}

t- statistics in parentheses corrected for heteroschedasticity when detected

** $=$ significant at $1 \%$ level

$*=$ significant at $5 \%$ level

(a) significant dummies only are reported

Table 6 shows that the picture changes substantially. The coefficients of all educational variables are no longer significant and the signs of both primary 
and secondary education are reversed. The dummy for Italy is significant at the one per cent level in all regressions suggesting that some unknown country specific factor correlated with the educational variables is at work which influences the rate of growth of productivity ${ }^{17}$.

Fig. 1. Total average years of schooling. Recursive estimation

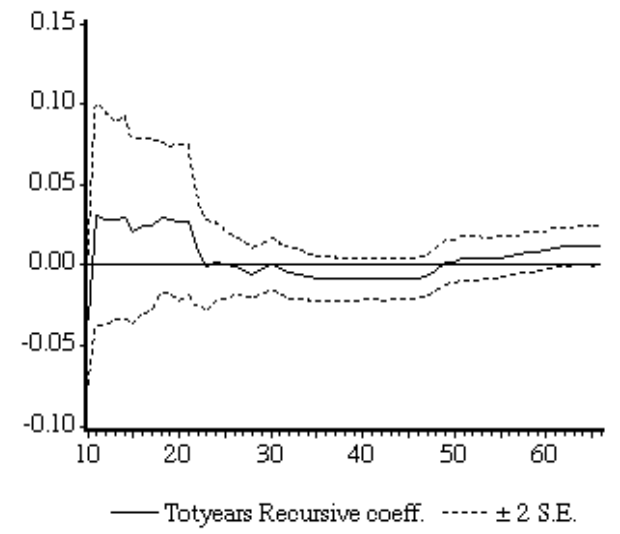

Fig. 2. Average years of secondary schooling. Recursive estimation

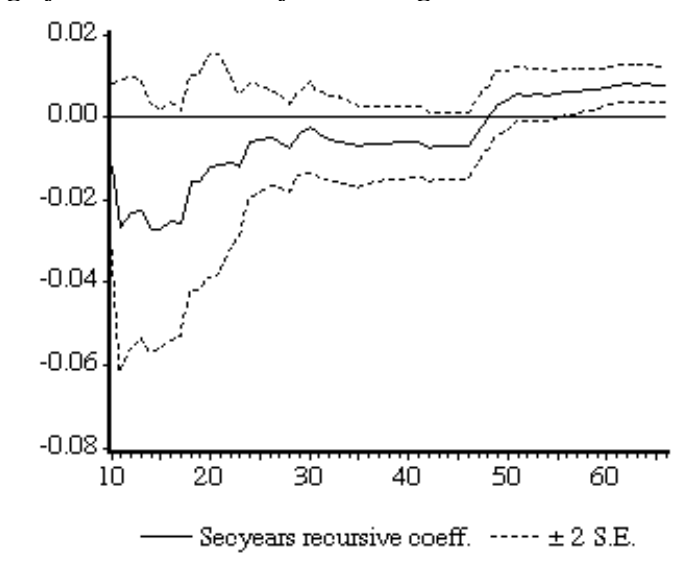

${ }^{17}$ Similar results were obtained using the shares of primary, secondary and higher education. They are not reported for brevity. 
Fig. 3. Average years of higher education. Recursive estimation

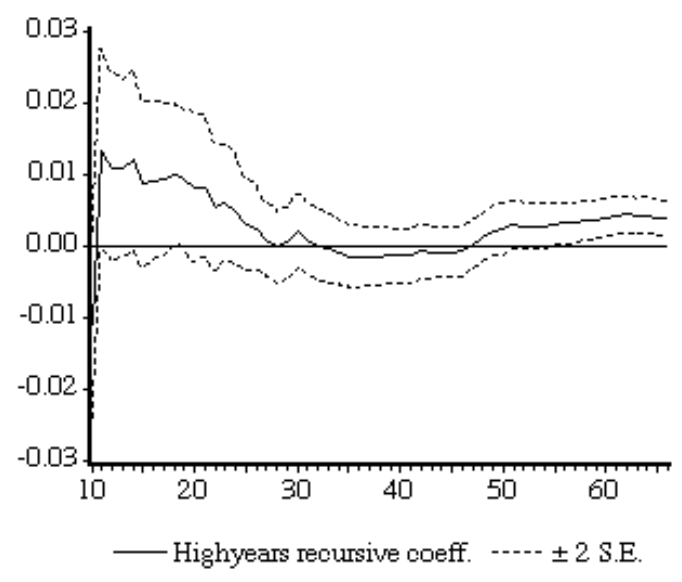

Further evidence on the stability of the coefficients of the educational variables can be obtained running a recursive estimation of the standard equation. In figure 1, 2 and 3 above the recursive coefficients estimates of the average years of total, secondary and higher education are plotted. The signs of the coefficients are very sensitive to changes in the sample. The last twenty observations are the Italian regions. It is easy to check that the signs of the three coefficients change from negative to positive when these regions enter the sample.

\section{Educational skills, allocation and growth}

How can we interpret such evidence? Some limitations of the analysis must be taken into account: first the sample is not completely representative of the European Union regions since only Italy is included among southern countries. Furthermore the time span is perhaps too short to analyze an essentially long run relationship. Nevertheless the evidence suggests some considerations. It confirms that in industrialized countries the role of education as such in the growth and convergence processes is much more controversial than commonly suggested by theoretical literature. D rawing from the threshold hypothesis quoted in section 1 it is possible to argue that in backward economies education is a fairly good proxy of the human capital input because it provides basic skills, and their diffusion in the labour force is crucial in terms 
of growth performance. When growth depends on more specialized and sophisticated skills as in industralized economies, a generic measure of education is too rough to capture the complex links between human capital and growth.

Disaggregating the educational measure to take account of different levels of education and of their separate effects on growth does not change the picture but adds some interesting information and raises further questions. Particularly problematic is the fact that empirical evidence assigns a marginal or no role to higher education. While literacy or primary education might be crucial skills in low income countries, in industrialized ones, where innovation drives growth, the adoption of new technologies is more and more requiring in terms of educational skills. Scientific and computing skills as well as professional ones play a dominant role in information economies thus implying the primary importance of university education.

If this quite plausible hypothesis is not supported by the empirical evidence one possible explanation is that education as such is not the correct proxy we are searching for to explain the relationship between human capital and growth. Actually not all skills acquired with higher education contribute in the same way to the growth of the economy. This certainly applies to those mentioned above but is not necessarily true for other types of skills which can produce substantial pay offs at the individual level although applied to growth neutral or even harmful activities such as rent seeking. This implies that the rate of growth should be affected not by the educational skills of the whole labour force but mainly by those embodied in the share of it occupied in innovative activities. To test this hypothesis we add to the regressors the variable $\mathrm{TEC}^{18}$, a measure of the share of the active population allocated to scientific and technical occupations requiring mostly higher or, at least, upper secondary education.

In table 7 the coefficient of the variable TEC is always significant at the one per cent level. Its impact on the rate of growth of productivity is not very different from the educational measures, while the speed of convergence increases a little holding it constant. The overall fit of the regression improves too as can be seen from the value of the R squared which jumps from 0.26 in the case of unconditional convergence to 0.45 . The most important difference however is that this is a very robust variable. The coefficient remains strongly significant when country dummies or other variables are added to the

\footnotetext{
${ }^{18}$ The method adopted for constructing this variable is described in section 2 above.
} 
regressors.

In regression 2 and 3 a measure of $R \& D$ activity has been introduced ${ }^{19}$, to test whether the latter is a better proxy of the human capital allocated to innovative activities. In regression 2 its coefficient is positive and significant at the five per cent level but the impact on productivity growth is rather weak, moreover the explanatory power of the model is very low. Adding TEC to the equation the coefficient of the R\&D variable becomes insignificant suggesting that there is some degree of collinearity between the two variables but the former is a better explanator of productivity growth. For similar reasons we control also for the share of industrial employment. Since most technical skills are concentrated in this sector of the economy the variable TEC may capture structural effects due to the distribution of the labour force among the main sectors of the economy. In this case too the econometric results in regression 4 confirm the robustness of the variable of interest.

${ }^{19}$ It is the share of R\&D personnel in business enterprises per 1000 labour force. The source is the databank Regio 2. The available data consist of one annual observation for 1985. As for investment rates Eurostat does not provide data for United Kingdom. 
Table 7. Convergence in productivity with share of technical occupations, $R \& D$, share of industrial employment and country dummies. 1981-91

Dependent variable is the average rate of growth of value added per worker 1981-91

Estimation method OLS

\begin{tabular}{|c|c|c|c|c|c|}
\hline & 1 & 2 & 3 & 4 & 5 \\
\hline CONSTANT & $\begin{array}{l}0.266 \\
(10.14)\end{array}$ & $\begin{array}{l}0.189 \\
(2.73)\end{array}$ & $\begin{array}{l}0.299 \\
(4.03)\end{array}$ & $\begin{array}{l}0.256 \\
(8.34)\end{array}$ & $\begin{array}{l}0.208 \\
(6.57)\end{array}$ \\
\hline L0GVA81 & $\begin{array}{l}-0.021 \\
(-8.55)^{* *}\end{array}$ & $\begin{array}{l}-0.016 \\
(-2.36)^{*}\end{array}$ & $\begin{array}{l}-0.024 \\
(-3.55)^{* *}\end{array}$ & $\begin{array}{l}-0.020 \\
(-7.22)^{* *}\end{array}$ & $\begin{array}{l}-0.016 \\
(-5.82)^{* *}\end{array}$ \\
\hline LOGTEC & $\begin{array}{l}0.010 \\
(4.30)^{* *}\end{array}$ & & $\begin{array}{l}0.009 \\
(2.36)^{*}\end{array}$ & $\begin{array}{l}0.010 \\
(5.22)^{* *}\end{array}$ & $\begin{array}{l}0.006 \\
(3.10)^{* *}\end{array}$ \\
\hline LOGRD & & $\begin{array}{l}0.001 \\
(2.43)^{*}\end{array}$ & $\begin{array}{l}0.001 \\
(1.33)\end{array}$ & & \\
\hline LOGINDEMP & & & & $\begin{array}{l}-0.001 \\
(-0.07)\end{array}$ & \\
\hline $\operatorname{DUMIT}^{(\mathrm{a})}$ & & & & & $\begin{array}{l}-0.004 \\
(-4.44)^{* *}\end{array}$ \\
\hline $\operatorname{DUMGE}^{(\mathrm{a})}$ & & & & & $\begin{array}{l}0.002 \\
(2.00)^{*}\end{array}$ \\
\hline R2 adj. & 0.45 & 0.12 & 0.21 & 0.47 & 0.57 \\
\hline F test & 27.9 & 4.70 & 5.7 & 20.2 & 23.0 \\
\hline Num.obs. & 66 & 54 & 54 & 66 & 66 \\
\hline
\end{tabular}

t- statistics in parentheses corrected for heteroschedasticity when detected

$* *=$ significant at $1 \%$ level

$*=$ significant at $5 \%$ level

(a) significant dummies only are reported

To test more thoroughly the robustness of this variable an extreme bounds analysis has been conducted following the approach proposed by Levine and Renelt (1992). Four more Z variables have been included besides 
those already considered. They are measures of the share of the labour force in agriculture and services, the average rate of growth of labour units and the share of industrial investment on value added. The results reported in table 8 confirm the robustness of the variable of interest which maintains a positive and significant coefficient both at the higher and lower bound.

\section{Table 8. Sensitivity analysis}

D ependent variable is the average rate of growth of value added per worker 1981-91

Estimation method OLS

Number of observations: 66

Base equation: VAGROWTH = b0 + b1 LOGVA81 + b2 LOGTEC

Variable of interest: LOGTEC

\begin{tabular}{llllll}
\hline & Coeff. & S.E. & T-stat. & $\mathrm{R}^{2}$ adj. & Z variables \\
\hline High & 0.013 & 0.003 & $3.96^{* *}$ & 0.24 & LOG IND EMP,LOG INV \\
Base & 0.010 & 0.002 & $4.30^{* *}$ & 0.45 & \\
Low & 0.007 & 0.003 & $2.36^{*}$ & 0.40 & LOGRD, D UMMIES \\
\hline
\end{tabular}

** = significant at $1 \%$ level

$*=$ significant at $5 \%$ level

It may be objected to these results that the causal relationship between growth and the active population occupied in technical activities runs the other way around: from growth to technical occupations. While it takes long time for the share of higher education to adjust to the growth rate, even if enrollment rates are very responsive to the latter, because students must first complete their studies then the new cohorts of skilled workers must substitute the older ones, it could be argued that it is easier to change occupation if pay offs are higher in those occupations more affected by the growth of the economy, or if the demand of particular skills required by the most dynamic sectors of the economy grows at a faster rate. 
Table 9. Convergence in productivity among the European regions. Share of active population occupied in technical activities. 1983-91

\begin{tabular}{lrrr}
\hline LOGVA83 & LOGTEC83 & R2 & F \\
\hline $\begin{array}{r}-0.012 \\
(-3.45)^{* *}\end{array}$ & -0.005 & 0.15 & 6.6 \\
\hline & $(2.46)^{*}$ & & \\
$* *$ significant at $1 \%$ level & & & \\
$*=$ significant at the $5 \%$ level & & &
\end{tabular}

To take this possibility into account we ran some regressions using the initial values of the variable TEC. Unfortunately it is not possible to cover the same period since the available data start from 1983, however the relationship has been estimated for the period 1983-91. The variable under test performs rather well though both the coefficient and the $\mathrm{R}$ squared are lower than in the previous regressions.

\section{Concluding remarks}

Since this paper is not addressed to testing a specific theoretical model the reported results are at best only suggestive. Nevertheless, in our opinion, they confirm that pursuing this line of analysis can shed light on some aspects of the controversial relationship between human capital and economic growth. The main findings can be summarized as follows.

There is no clear evidence of a significant partial correlation between the educational attainment of the labour force and the rate of growth of productivity. When a significant relationship has been found it seems to depend on the fact that the educational variables capture the effects of some country specific omitted variable on the rate of growth of productivity.

Disaggregating education adds little to the picture. Neither secondary schooling nor higher education have significant effects on the rate of growth once country dummies are included among the regressors. Particularly the finding that higher education plays no role in productivity growth and convergence contrasts with the predictions of most theoretical literature on the subject.

The hypothesis tested here to explain these anomalous results is that the allocation of educated labour force to different activities must be taken into account because not all them contribute to the overall growth of the economy. The findings of this paper give some support to this explanation. They show 
that a significant and robust correlation exists between the rate of growth of productivity and a measure of the educated labour force occupied in technical activities.

Needless to say this is not the only explanation of why empirical analysis fails to get firm conclusions about the contribution of human capital to economic growth. Several arguments have been proposed to explain this anomaly as reported in section one. What our results suggest is that we should look further into the microeconomics of individual's choice of activity because this is a crucial factor underlining the relationship between human capital and growth. Since this choice is very much determined by the structure of incentives and pay offs in the economy, and these in turn are shaped by institutions we need to bring the latter into the stage to understand better the complex dynamics of economic development.

\section{Bibliography}

Azariadis, C. and Drazen, A. (1990). Threshold Externalities and Economic D evelopment. QuartelyJamal of Ecommics 501-526

Barro R.J. (1991), Economic Growth in a Cross-section of Countries, Quartely Jaumal of Economics Vol.106, n.2, pp. 407-43.

Barro R.J. (1996), Determinants of Economic Growth: A Cross-Country Empirical Study, NBER Working Paper n. 5698.

Baumol W.J. (1990), Entrepreneurship: Productive, Unproductive and Destructive, Jaumal of Pditical Econmy, Vol. 98, n. 5, pp. 893-921.

Benhabib, J. and Spiegel, M.M. (1994), The Role of Human Capital in Economic Development: Evidence from Aggregate Cross-Country Data. Jaumal of Montary Economics 34, pp. 143-173.

Bils M., Klenow P.J. (1995), Does Human Capital Drive Growth or the Other Way Around?, mimeo

Fagerberg J., Verspagen B. (1996), Heading for Divergence? Regional Growth in Europe Reconsidered, Journal of Common Market Studies, Vol. 34, n. 3, pp. 431-48

Islam N. (1995), Growth Empirics: A Panel D ata Approach, QuartelyJarmal of Economics, Vol.

Jorgenson D.W., Fraumeni B.M. (1992), Investment in Education and U.S. Economic G rowth, ScandinavianJaumal of Ecommics Supplement pp. 51-70.

Klenow P., Rodriguez-Clare A., The Neoclassical Revival in Growth Economics: Has it Gone too Far?, NBER 1997 Macroeconomics Annual, forthcoming.

Kyriacou G.A. (1991), Level and Growth Effects of Human Capital: A Cross-Country Study of the Convergence Hypothesis, C.V. Star Center for Applied Economics, Economic Research Reports n 91-26. 
Laband D.N., Sophocleus J.P. (1987), The Social Cost of Rent Seeking: First Estimates, Economa ddleScitePubbliche May-August, pp. 127-33.

Levine R., Renelt D. (1992), A Sensitivity Analysis of Cross Country Growth Regressions, AmmicanEconmicReiew Vol.82,n.4, pp. 943-63.

Magee S.P., Brock W.A., Young L. (1989), Black Hole Tariffs and Endogenous Policy Theory. Political Economy in G eneral Equilibrium, Cambridge University Press.

Mankiw N.G., Romer D., Weil D.N. (1992), A Contribution to the Empirics of Economic Growth, QuartelyJaumal of Economics Vol. 107, May pp. 408-37.

Murphy K.M., Shleifer A., Vishny R.W. (1991), The Allocation of Talent: Implications for $\mathrm{G}$ rowth, QuartelyJaumal of Econmiss n.2, pp. 503-30.

Nehru, V., Swanson, E. and Dubey, A. (1995), A new database on human capital stocks in developing and industrial countries: sources, methodology and results, Jaumal of Dexdopment Economiss 46(2), pp. 379-401.

North D., (1990), Institutions, Institutional Change and Economic Performance, Cambridge University Press.

Paci R. (1996), More Similar and less Equal. Economic Growth in the European Regions, Contributi di Ricaca Crenos 96/ 9.

Pritchett, L. (1995). Where has all the education gone? World Bank working paper no. 1581.

Romer P. (1990), Human Capital and Growth: Theory and Evidence, CamejeRohester ConferenceSeries on PublicPdioy, 32, 251-286.

Wolff E.N., Gittleman M. (1993), The Role of education in Productivity Convergence: D oes Higher Education Matter?, in Szimai A., Van Ark B., Pilat D., Explaining EconomicGrouth Elsevier.

Wolff H.C. (1994), Growth Convergence Reconsidered, Wetwintshaftlidhes Archiv, Vol. 130, n. 4, pp. 747-59. 